\title{
Review of Surgical Outcomes between Plate and Screw Fixations in Lapidus Procedure for Asians' with Hallux Valgus
}

\author{
${ }^{1}$ Huang Y Lun, ${ }^{2}$ Bryan Loh, ${ }^{3}$ Lee K Hwee, ${ }^{4}$ Koo Kevin, ${ }^{5}$ Inderjeet R Singh
}

\begin{abstract}
Background: This study aims to evaluate the clinical outcomes of the Lapidus procedure utilizing either plate osteosynthesis or screw fixation in a significantly sized patient group with a minimum of 2 years follow-up.
\end{abstract}

Materials and methods: This is a retrospective analysis of prospectively collected data of 68 consecutive hallux valgus in 56 patients who underwent the Lapidus procedure with a plate (Synthes X plate 38 feet) or screw fixation (29 feet) by a single surgeon in a single institution from 2007 to 2011. Patients were followed up at 6 months and 2 years and evaluation included clinical assessment, weight-bearing radiographs, and patientreported outcome measures, namely pain visual analog score (VAS), American Orthopedic Foot and Ankle Society (AOFAS) hallux score.

Results: In the plate osteosynthesis group, the VAS score improved significantly from 5.09 to $0.94(p<0.001) 2$ years postoperatively. Similarly, the AOFAS hallux score improved significantly from 53.5 to 83.7 ( $p<0.001$ ) 2 years postoperatively. In the screw fixation group, the VAS score improved significantly from 4.68 preoperatively to $1.74(p=0.03) 2$ years postoperatively. Similarly, the AOFAS hallux score improved significantly from 53.5 preoperatively to 76.6 ( $p<0.001) 2$ years postoperatively. Comparing the two groups, there was no difference in the improvement of VAS and AOFAS hallux scores. Similarly, at 2 years, there was no difference between the groups regarding patient's satisfaction and expectations.

Conclusion: The Lapidus procedure utilizing either plate osteosynthesis or screw fixation is a reliable and safe option for hallux valgus, with good clinical outcomes and low complication rates.

Level of evidence: Level II

Keywords: Hallux valgus, Lapidus arthrodesis first metatarsophalangeal joint, Screw fixation, X-plate fixation.

How to cite this article: Lun HY, Loh B, Hwee LK, Kevin K, Singh IR. Review of Surgical Outcomes between Plate and Screw Fixations in Lapidus Procedure for Asians' with Hallux Valgus. J Foot Ankle Surg (Asia Pacific) 2018;5(2):64-67.

Source of support: Nil

Conflict of interest: None

\footnotetext{
1,2 Medical Officer, ${ }^{3,4}$ Associate Consultant, ${ }^{5}$ Senior Consultant

${ }^{1-5}$ Department of Orthopedics, Singapore General Hospital, Singapore
}

Corresponding Author: Bryan Loh, Medical Officer, Department of Orthopedics, Singapore General Hospital, Singapore, e-mail: zantesuken@hotmail.com

\section{INTRODUCTION}

Lapidus procedure or the arthrodesis of the first tarsometatarsal joints (TMTJ) is a widely used procedure for the correction of hallux valgus (HV) deformity. It has proven to be a safe and highly effective procedure. ${ }^{1,2}$ The Lapidus procedure is also effective in correcting recurrent $\mathrm{HV}$ with a low non-union rate and excellent radiographic correction, with a high percentage of patients satisfied with their outcome. ${ }^{3}$

Many osteosynthetic methods for arthrodesis have been described. Plate fixation has been shown to be stronger and stiffer when compared to intramedullary fixation, thus reducing the risk of non-union and shortening the period of a non-weight bear, ${ }^{4}$ thus proving to be a good alternative to screw fixation. ${ }^{5}$ When used as an adjunct to lag screw fixation, locking plate augmentation for Lapidus arthrodesis allows for early weight-bearing with satisfactory outcomes, improved clinical and radiographic alignment, and improved AOFAS scores. ${ }^{6-9}$ Cadaveric studies have shown that the increasingly more popular dorsomedial H-shaped plating system and plantar platings are both safe and well-established procedures with the latter shown to have a lower risk of injury to neurovascular structures and biomechanically superior. ${ }^{10,11}$

Non-union has always been one of the most dreaded complications of the Lapidus procedure. Fortunately, it is not a common occurrence. Studies have shown that non-union rates range from 3.6 (staple fixation) ${ }^{12}$ to $5 \%$ (compression screw fixation), ${ }^{13}$ even when performed by experienced surgeons.

However, there is few available published data providing information on the superior method of fixation for the fusion of the first TMTJ, in vivo. Our study aims to evaluate the clinical outcomes of the Lapidus procedure utilizing either plate osteosynthesis or screw fixation in our cohort of patients with a minimum of 2 years follow-up.

\section{Surgical Technique}

The patient is placed supine, and a tourniquet is applied around the thigh. An incision is performed over the dorsum of the foot medial to the extensor hallucis longus tendon (EHL). The EHL is mobilized laterally to facilitate 
the exposure of the TMTJ, via a subcapsular and subperiosteal dissection, after incising the first TMTJ capsule longitudinally.

The first TMTJ joint is exposed completely allowing for the complete removal of the articular cartilage using a microsagittal saw to cut the distal medial cuneiform articular surface and opposing 1st metatarsal articular surface. The cuts are planned to result in a congruent surface so that the resected first TMTJ surfaces match up well to realign the first metatarsal, thus correcting the hallux valgus. After positioning the first TMTJ joint in a satisfactory position, the joint is then fixed with three $2.7 \mathrm{~mm}$ cortical screws placed across the fusion site in lag fashion. For plate fixation, the plate is positioned dorsal-medial to the first TMTJ, with the locking screws inserted sequentially.

Distally, the modified Mcbride procedure is performed to augment the correction of hallux valgus, with excision of the bunion and medial capsular plication. A lateral capsulotomy is done via a separate incision at the first web space together with a complete release of the adductor hallucis from its insertion at the base of the proximal phalanx

Postoperatively, the screw fixation group was placed on a non-weight bearing regime with Dutch boot type foot cast for 6 weeks, whereas the plate fixation group was placed on partial weight bearing with heel wedge shoes for 6 weeks.

The surgeon started out by using three $2.7 \mathrm{~mm}$ screws to achieve a fusion of the first TMTJ as part of the procedure to correct the hallux valgus. When the $X$-plate became available, the X-plate was used in place of the interfragmentary screws, with all other parts of the procedure remaining the same. The change in part of the operative procedure was because many patients did not like the Dutch boot type foot cast, as it was uncomfortable

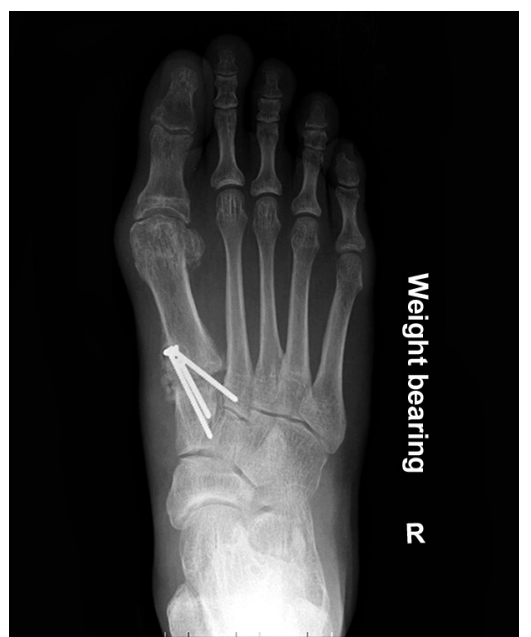

Fig. 1: X-ray of post Lapidus procedure with plate osteosynthesis in our hot climate. With the X-plate method of fixation, a cast of any sort was unnecessary and only a heel wedge shoe was used.

\section{MATERIALS AND METHODS}

This study had approval from the hospital's ethics board and written informed consent was obtained from all the patients.

A retrospective analysis of prospectively collected data of 68 consecutive feet with hallux valgus in 56 patients who underwent Lapidus procedure with either plate (Synthes X-plate, Synthes, Oberdorf, Switzerland) or screw fixation by a single surgeon in a single institution from 2007 to 2011.

Postoperatively, the patients were followed-up regularly at 3,6,12 and 24 months interval, and evaluation included clinical assessment, weight-bearing radiographs (Figs 1 and 2) and patient-reported outcome measures, namely pain VAS, AOFAS hallux score.

Radiological assessment of fusion was assessed by the attending surgeon and his orthopedic resident. If there is suspicion of non-union with a history of persistent pain over the first TMTJ and absence of bridging callous, computed tomography will be performed. Clinical outcome scores were recorded at the orthopaedic diagnostic center by independent assessors before surgery, at 6 months and 2 years postoperatively.

\section{Statistical Analysis}

Statistical analysis was carried out using SPSS® 19.0 (IBM, Armonk, New York, United States). Statistical significance was defined as a $p$-value of $\leq 0.05$. The Student's paired t-test was used to analyze the improvement in VAS and AOFAS scores in both the plate osteosynthesis and screw fixation group.

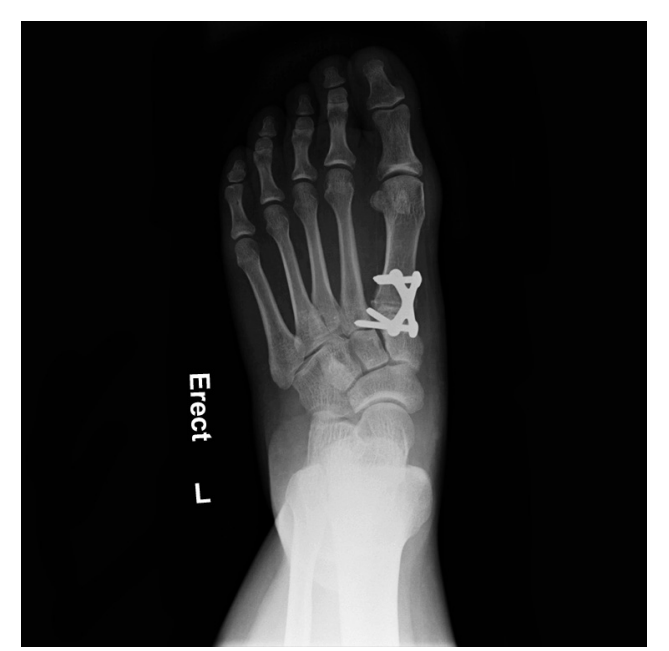

Fig. 2: X-ray of post Lapidus procedure with screw fixation 


\section{RESULTS}

There were 39 feet treated with X-plate osteosynthesis and 29 with screw fixation. The mean age of patients for plate osteosynthesis was 47.1 years and screw fixation was 48.9 years $(\mathrm{p}>0.05)$ (Table 1$)$.

In the plate osteosynthesis group, the VAS score improved significantly from 5.09 preoperatively to $0.94(p=0.00) 2$ years postoperatively. Similarly, the AOFAS hallux score improved significantly from 53.5 preoperatively to $83.7(\mathrm{p}=0.00) 2$ years postoperatively. In the screw fixation group, the VAS score improved significantly from 4.68 preoperatively to $1.74(\mathrm{p}=0.03) 2$ years postoperatively. Similarly, the AOFAS hallux score improved significantly from 53.5 preoperatively to 76.7 $(p=0.00) 2$ years postoperatively (Table 2 and Graphs 1 and 2).

Comparing the 2 groups, there was no significant difference in age, body mass index (BMI) and gender between the two groups $(p>0.05)$. There was also no difference between the groups regarding patient's satisfaction and expectations. In the $X$-plate group, the union rate was $89.7 \%$ (35/39 feet), with four symptomatic patients undergoing revision surgery with bone grafting. In the screw fixation group, the union rate was $89.7 \%(26 / 29$ feet), with one symptomatic patient undergoing revision surgery. However, there was a relatively common incidence of broken screws in the screw fixation group (39.7\%, 11/29 feet), in which three patients underwent screw removal. The surgical correction for hallux valgus was preserved on all follow-up radiographs.

Table 1: Number of patients recruited into each arm of our study and mean age

\begin{tabular}{lll}
\hline & X-plate & Screw \\
\hline No. of patients & 39 & 29 \\
Mean age (years) & 47.1 & 48.9 \\
\hline
\end{tabular}

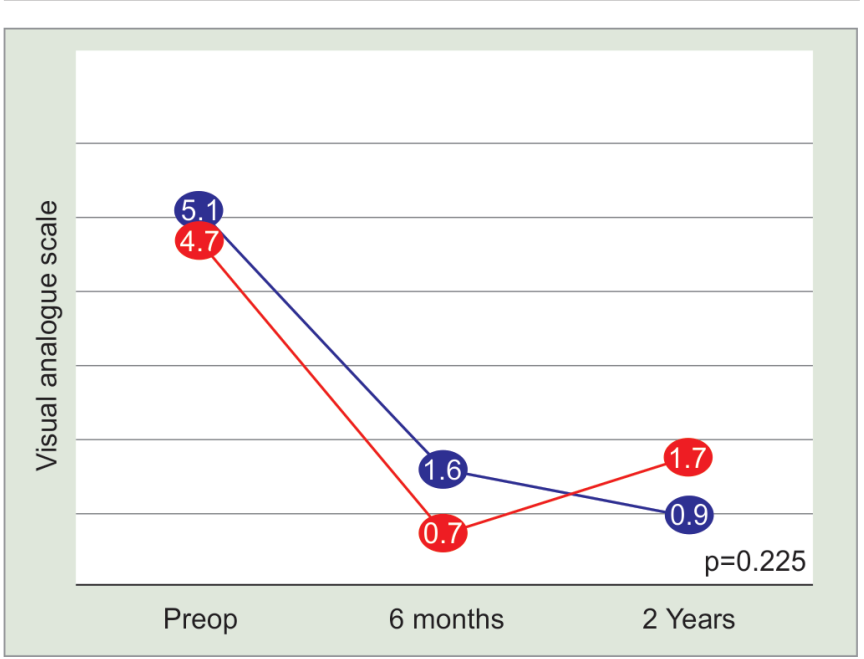

Graph 1: Chart demonstrating VAS over 2 years follow up period for both plate osteosynthesis and screw fixation groups of patients.

\section{DISCUSSION}

Literature has shown Lapidus to be a valuable procedure that has high levels of patient satisfaction with few complications..$^{1-3}$ Analysis of our data shows similar findings. However, many different osteosynthetic methods of arthrodesis have been described, but none has been proven to be superior. ${ }^{1-3,9,13}$ For screw fixation, Ellington et al. reported good radiological fusion of $96 \%$, and a systemic review by Donnenwerth showed low nonunion rates of $5 \%{ }^{3,13}$ For plate fixation, to the best of our knowledge, there are no substantial published results of Lapidus procedure with plating alone.

Currently, there is also a paucity in the literature data comparing the results of screw fixation vs. plate osteosynthesis in performing arthrodesis of the first metatarsalcuneiform joint. Hence there is a need for more studies to ascertain the benefits and risks between these two methods. ${ }^{8}$ We hope to contribute to this by reporting on one of the largest currently available series comparing the clinical and radiological outcomes of the two procedures with a minimum follow-up of 2 years.

From our study, there is no difference found between union rates, improvement in VAS and AOFAS hallux scores and patient satisfaction between the two groups of

Table 2: VAS, AOFAS scores and union rates of the 2 groups of patients

\begin{tabular}{lllll}
\hline & X-plate & \multicolumn{3}{c}{ Srcew } \\
\hline & Pre-op & $\begin{array}{l}\text { 2 year } \\
\text { post-op }\end{array}$ & Pre-op & $\begin{array}{l}\text { 2 year } \\
\text { post-op }\end{array}$ \\
\hline VAS & 5.09 & 0.94 & 4.68 & 1.74 \\
AOFAS & 53.5 & 83.7 & 53.5 & 76.6 \\
hallux & & & & \\
$\begin{array}{l}\text { score } \\
\text { Union }\end{array}$ & 89.7 & & 89.7 & \\
rates (\%) & & & & \\
\hline
\end{tabular}

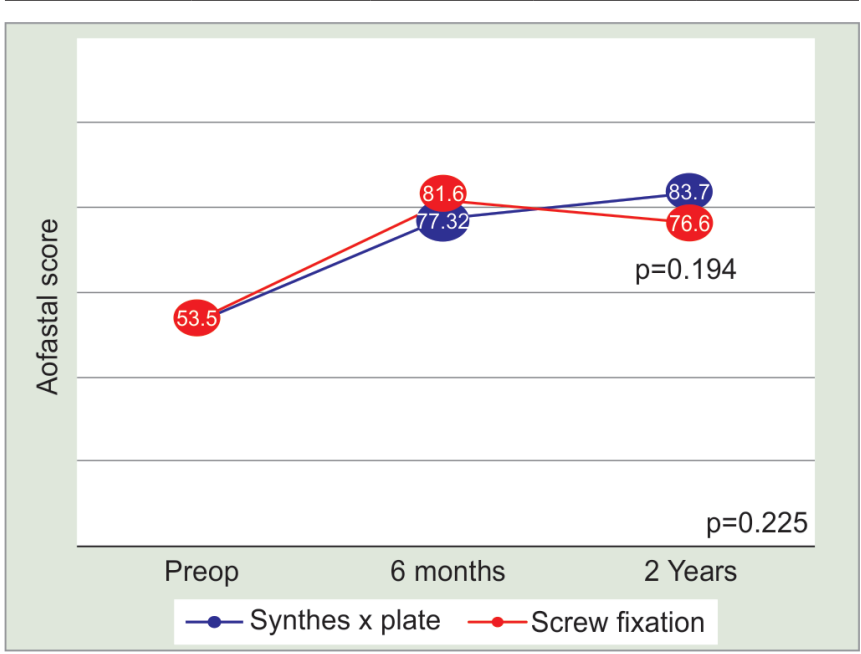

Graph 2: Chart demonstrating AOFAS hallux score over 2 years follow-up period for both plate osteosynthesis and screw fixation groups of patients. 
patients at 2 years follow-up. However, there is a noticeable proportion of patients who underwent screw fixation who had broken screws $(40 \%)$ with a small proportion needing a second surgery to remove them. This may highlight a higher incidence of delayed union, with a small percentage going to eventual non-union. This may prove to be an important preoperative counseling point for patients who opted for screw fixation.

Interestingly, the results of our study differ from that by DeVries et al., who reported superior clinical and radiological outcomes with dorsal-medial plating as compared to screw construct. However, in the plating group, some patients also had compression screw fixation, which may account for the difference in outcomes ${ }^{8}$

The limitation of this study is that there are inherent selection and observer biases as the patients are recruited from a single tertiary hospital. Secondly, there is no available information about the types of subsequent physical activities of the patients after the completion of the hospital's standard postoperative physiotherapy protocol. These subsequent physical activities can influence the functional outcome after Lapidus procedure.

Lastly, the follow up in this study is 2 years, and a longer follow-up will give us the information on the maintenance of correction of hallux valgus by the Lapidus procedure, done by the two methods described in this report.

\section{CONCLUSION}

We conclude that the Lapidus procedure utilizing either plate osteosynthesis or screw fixation is a reliable and safe option for hallux valgus, with good clinical outcomes and low complication rates

\section{REFERENCES}

1. Taylor NG, Metcalfe SA. A review of surgical outcomes of the Lapidus procedure for treatment of hallux abductovalgus and degenerative joint disease of the first MCJ. Foot (Edinb). 2008 Dec;18(4):206-210.

2. Coetzee JC, Wickum D. The Lapidus procedure: a prospective cohort outcome study. Foot Ankle Int. 2004 Aug;25(8):526-531.

3. Ellington JK, Myerson MS, Coetzee JC, Stone RM. The use of the Lapidus procedure for recurrent hallux valgus. Foot Ankle Int. 2011 Jul;32(7):674-680.

4. Roth KE, Peters J, Schmidtmann I, Maus U, Stephan D, Augat P. Intraosseous fixation compared to plantar plate fixation for first metatarsocuneiform arthrodesis: a cadaveric biomechanical analysis. Foot Ankle Int. 2014 Nov;35(11):1209-1216.

5. Young NJ, Zelen CM. New techniques and alternative fixation for the lapidus arthrodesis. Clin Podiatr Med Surg. 2013 Jul;30(3):423-434.

6. Cottom JM, Vora AM. Fixation of lapidus arthrodesis with a plantar interfragmentary screw and medial locking plate: a report of 88 cases. J Foot Ankle Surg. 2013 Jul-Aug;52(4):465469.

7. Menke CR, McGlamry MC, Camasta CA. Lapidus arthrodesis with a single lag screw and a locking H-plate. J Foot Ankle Surg. 2011 Jul-Aug;50(4):377-382.

8. DeVries JG, Granata JD, Hyer CF. Fixation of first tarsometatarsal arthrodesis: a retrospective comparative cohort of two techniques. Foot Ankle Int. 2011 Feb;32(2):158-162.

9. Klos K, Gueorguiev B, Mückley T, Fröber R, Hofmann GO, Schwieger K, Windolf M. Stability of medial locking plate and compression screw versus two crossed screws for lapidus arthrodesis. Foot Ankle Int. 2010 Feb;31(2):158-163.

10. Simons P, Fröber R, Loracher C, Knobe M, Gras F, Hofmann GO, Klos K. First Tarsometatarsal Arthrodesis: An Anatomic Evaluation of Dorsomedial Versus Plantar Plating. J Foot Ankle Surg. 2015 Sep;54(5):787-792.

11. Klos K, Simons P, Hajduk AS, Hoffmeier KL, Gras F, Fröber R, et al. Plantar versus dorsomedial locked plating for Lapidus arthrodesis: a biomechanical comparison. Foot Ankle Int. 2011 Nov;32(11):1081-1085.

12. Mallette JP, Glenn CL, Glod DJ. The incidence of non-union after Lapidus arthrodesis using staple fixation. J Foot Ankle Surg. 2014 May-Jun;53(3):303-306.

13. Donnenwerth MP, Borkosky SL, Abicht BP, Plovanich EJ, Roukis TS. Rate of non-union after first metatarsal-cuneiform arthrodesis using joint curettage and two crossed compression screw fixation: a systematic review. J Foot Ankle Surg. 2011 Nov-Dec;50(6):707-709. 